\title{
“It's just not worth a damn!" Investigating perceptions of the value in attending university
}

\author{
Steve Cook ${ }^{1}$, Duncan Watson ${ }^{2}$ and Rob Webb ${ }^{3}$
}

\begin{abstract}
Mass expansion of the UK Higher Education (HE) sector is eroding its well documented benefits - leading many to question whether HE remains worthwhile. Avoiding the traditional approach of estimating the returns to HE, we investigate why many now feel that attending university will not yield any financial benefits. Using BSA data from 2010 we find that this negativity is being driven by perceived lack of graduate job prospects, the rise in tuition fees and wage underpayment. We conclude that this may well fuel uncertainty and reduce demand for HE from lower socio-economic groups while increasing intra class conflict in higher socio-economic groups.
\end{abstract}

Keywords: Higher Education; Graduate Premium; Massification; Attitudes; Underpayment

${ }^{3}$ Corresponding Author: Nottingham University Business School, University of Nottingham, Jubilee Campus, Wollaton Road, NG8 1BB, robert.webb@nottingham.ac.uk, 0115 8230588; 2School of Economics, University of East Anglia, Norwich Research Park, Norwich, NR4 7TJ, duncan.watson@uea.ac.uk, $01603593275 ;{ }^{1}$ School of Management, Swansea University, Bay Campus, Swansea SA1 8EN, s.cook@swansea.ac.uk, 01792) 602106 


\section{Introduction}

Over the past decades there has been a consensus regarding the positive benefits to both individuals and society of expanding UK higher education (HE). This has led to a massive growth in the sector, resulting in over 420,000 students graduating with a bachelor degree in 2015 compared to just over 77,000 in 1990 (HESA https://www.hesa.ac.uk and Bolton 2012). Such expansion has led us to both perceive and use HE differently, using it less and less to become learned and increasingly to signal our competence to potential employers to secure a well remunerated job. As a result, much of the research in this area of HE has focused primarily upon the personal financial value, or 'graduate earnings premium' of those attending university (see Vignoles and Murray 2016 for an introduction).

This paper takes an alternate approach, examining an area where there seems to be a dearth of research - the perceptions of the financial value of a bachelor degree, investigating answers to the question 'do you think a degree is actually worth it? Of course, a little research does exist in this area, even if tangentially, for example the work of Mountford-Zimdars, Jones, Sullivan and Heath (2013) and more recently Webb et al (2015). We use the British Social Attitudes survey 2010 in order to examine answers and characteristics of individuals to questions including expanding; the importance; the worth; the financial remuneration; job opportunities and the holistic nature of HE. We begin by looking into the literature that may well have the most influence on perceptions of the value of higher education - that is, studies examining the financial returns to higher education, known as the graduate premium, and then look into any reported non-financial returns to higher education. We examine past literature regarding the level of the graduate premium, its reported erosion over the past few years and issues regarding the methodologies used to calculate the premium. All of which may generate expectations that do not materialise. The section finishes by examining theories as to why the premium may be declining and how massification is evolving perceptions. We then introduce our methodology, results and conclusions.

\section{The Declining Value of Higher Education?}

The sheer weight of consensus during (at least) the past four or five decades regarding the benefits of attending a HE institution, studying for, and gaining a first degree has been crushing. Politicians, academics and social commentators have argued that studying for a degree only has positive benefits and that access should not be restricted to an elite few (see Economics of 
Education Review Volume 30, 2011 for an introduction to this debate). Such consensus is based upon benefits which, at first glance, have a clear rationale: that individuals gain access to higher levels of prosperity and a 'graduate earnings premium' (see for example, Naylor et al 2015). In addition, it is argued that society is enhanced both economically, via greater productivity and global economic competitiveness, and socially, via a more knowledgeable population (see Department for Education and Skills 2006).

Much research has been completed on the so called 'graduate earnings premium' (see Dickson and Harmon 2011 for a brief review). Back in 2003, Greenaway and Haynes estimated the premium to be as high as $£ 410,000$ and in 2005 Blundell et al. reported a premium of 27 per cent (over a working lifetime) to those leaving education with a degree (compared to not having a degree) and 48 per cent if graduates were compared to those who leave school with no qualifications. More recently, estimates have become a little more conservative. For example, the work of Million+, based upon extensive research undertaken by Conlon and Patrignani (2011) for the Department for Business, Innovation and Skills (BIS) found that the 'earnings premium’ of a UK undergraduate degree (on average) was around 27 per cent (again, compared to an individual leaving education with two ' $\mathrm{A}$ ' levels or more) and that the average gross graduate premium is around $£ 125,000$ over a working lifetime. In addition, they reported that graduates were just over 3 per cent more likely to obtain a job. Walker and Zhu (2013 also for the BIS) concur with Conlon and Patrignani. The authors estimate that the return to a degree relative to $2+$ A-levels is $23 \%$ for men and $31 \%$ for women and that 'the likely impact on discounted lifecycle net earnings of having a degree, relative to not having a degree, is $28 \%$ for men (approximately £168k) and 53\% for women (approximately £252k) on average’ (page 6).

As regards the benefits to the UK economy, scholars argue that individual benefits also measurably help the wider economy. Conlon and Patrignani (2011 or see Million+ 2013) provide evidence that graduates have more stable employment and, coupled with the premium, increases tax returns to the Exchequer. They estimate that the average net benefit to the Exchequer per student is $£ 94,000$ and that for the entire 2010-2012 UK-domiciled cohort the Exchequer's net benefit will be more than $£ 28$ billion during the cohorts’ working lives. In addition, Brown (2013) and Thompson and Simmons (2013) argue that graduates exude greater productivity but also increase co-worker productivity via learning by imitation. For example, Battu et al. (2003) and Metcalfe and Sloan (2007) both report that untrained employees can increase their earnings by approximately 9-12 per cent by working alongside employees who 
have an additional year of education. Further, Moretti (2004) reports that a 1 per cent increase in graduates within a city can increase wages in that city by up to 1.9 per cent.

Million+ (2013) have argued that a degree not only provides access to a financial premium but also more fulfilling jobs and less dependency on state benefits. Such research on the nonpecuniary benefits of $\mathrm{HE}$ is rich, with academics examining whether going to university allows individuals to expand their horizons, learn in a different way in an alternate setting and/or benefit from interaction from peers with different perspectives (see Walker 2010). The benefits are again dispersed between the individual and the wider society, such that it is argued that graduates may not only profit from better health outcomes but will also be less likely to commit crime and more likely to be engaged in civic society (see The Department for Education and Skills 2006 or Lochner and Moretti 2004). Individuals can also benefit in less easily modelled ways such as personal and family health and happiness, increased fertility, enjoyment of a wider array of leisure activities, and better employment prospects and financial decisions (see Oreopoulos 2007 and Oreopoulos and Salvanes 2011). Research as far back as the eighties such as that by Haveman and Wolfe (1984) also associates education with improved health, more enjoyment, better life choices, a higher savings rate and more efficient choice of life partner.

However, despite what may seem like a consensus, such mass expansion seems to be eroding the benefits - for both the economy and the individual. Wolf, back in 2002 argued that the UK had long passed the point of actually requiring expansion to aid the health of the economy or for future growth. While acknowledging that developed countries benefited from a healthy HE sector, Wolf questioned continued growth, stating there was 'no obvious relationship between levels of university attendance and wealth, or growth rates, or productivity’. Recently, Lord Baker suggested that the UK has more workers who are over qualified than any other OECD country apart from Japan (see Lord Baker: The Skills Mismatch 2014 and also Kemp-King 2016).

Research by the The Complete University Guide suggests that the graduate premium has been cut by up to 30 per cent between 2009 and 2014 and that starting salaries have dropped by over 10 per cent between 2007-2012 (Jobbins 2014). The most damning attack on whether any of the purported benefits actually exist comes from Kemp-King (2016) in a detailed report for the Intergenerational Foundation. He refers to the research on the graduate premium being akin to 'crystal ball gazing', most notably asserting that the current research, pointing to a premium of 
around $£ 100,000$ over a working lifetime, equates to just over $£ 2,000$ per year - not enough to cover the annual interest on the average loan taken out by students to fund their studies. He argues:

Any politician that dangles the carrot of a graduate premium on future earnings to justify increases in student fees, interest rates on loans, or adjusting student loan repayment thresholds, should be challenged for gross mis-selling... a wide range of factors influence whether you are likely to receive a graduate premium. These include, amongst others, pre-university education, the institution you attended, socio-economic ${ }^{1}$ background, gender, ethnicity, subject choice, and degree result. On graduation economic factors then come to the fore, such as the supply of graduates, chosen career path, and conditions in the employment market. (page 4).

In line with Kemp-King, past research is also being attacked on the validity of the models and their interpretation. Adnett and Slack (2007) review the research regarding the paucity in the various methodological approaches used to calculate both pecuniary and non-pecuniary benefits (add in the non-pecuniary benefits). Problems common to the various approaches are missing data, omitted variables and measurement errors. Adnett and Slack note missing variables are likely to be more of an issue in niche cohorts where interpretation or overemphasis may well be high (Gorard 2008 recently highlighted this issue as regards more general education research). More obviously, isolating the influence of HE in an earning function remains problematic - whatever the choice of explanatory variables or methodological technique. Others have also highlighted a number of issues regarding the model or interpretation, including: non-monetary returns; individual efficacy/personal traits; choice of a less than optimal job (for example charity work); lack of a comparator group or downright luck in the job market. Further, endogeneity and causality remain issues (as they do in many applied economics models).

Concerns also surround the premium being calculated as an average figure. Authors have questioned whether the 'average' benefits are representative and randomly distributed across the population or whether some socio-economic classes benefit more than others. For example, Ramsey (2008) concluded that the average estimates, widely reported in the academic literature, may conceal so much variation around the mean that they may well be meaningless. As such decisions made using the average may well lead to disappointment later. Kemp-King (2016) goes on to suggest that the average may not be representative for a number of additional reasons including: attending the right school; completing an internship before attending university; social-economic class and family background (in line with work of Bourdieu

\footnotetext{
${ }^{1}$ For ease of interpretation we use 'socio-economic class' and 'class' as synonymous
} 
1971/1977) all increasing your chances of obtaining a well-paid job. In addition, research has found that the financial benefits to attending university are skewed towards the better universities (usually meaning a Russell Group university). For example, Vignoles et al. (2008) found there was a wage premium of circa 6 per cent per annum for attending a better university.

Reporting the average is important because if the average graduate premium is interpreted in society as indicative of the whole, people will make decisions based upon this consensus/average, only to find after graduating that it did not exist for them - thus affecting perceptions. Or, alternatively, they could well believe that the graduate premium would not exist for them, and therefore will not enter higher education. If the positive returns to higher education do not exist for all, due to the average being unrepresentative and this is ignored when reporting the premium in the media, it will affect perceptions of the value of higher education, especially to those socio-economic groups for which the average is not representative.

Brown (2013) introduces the idea of social congestion in order to explain why the graduate premium is in decline and attitudes towards HE are changing. He argues that massification of HE has meant that a degree provides less and less in terms of traditional benefits and strategic positioning and that all social-economic classes have become squeezed. As hundreds of thousands now graduate annually, 'congestion' now occurs in the labour market and over supply leads to less job opportunities and unemployment - there are just too many degrees chasing too few degree-level jobs. As a result, bachelor degrees are now less effective as a signal of quality to employers and have become the base level requirement of those seeking employment. This has led the higher socio-economic groups, as Kemp-King (2016) alludes to above, to increasingly utilize their cultural and social capital to secure employment alongside the tactical use of schooling, private tutoring and extra-curricular activities - to signal and influence employer outcomes in their favour. As such, congestion has led to covert game playing by these groups in order to maintain employment opportunities, access to the premium and their socio-economic position (see Bourdieu 1997 and Roulin and Bangerter 2013). As Brown states 'while everyone can do their best, not everyone can be the best...individual achievements are not judged in isolation, but in a positional competition that typically privileges those from higher social class' (page 682). As congestion occurs, changes in behaviour mean that the average premium is not shared across society and will affect attitudes regarding the financial worth of attending university. 
Attitudes have also been altered by the introduction in September 1998 of tuition fees of $£ 1,000$, which increased to a £3,000 top-up fee in 2004 and, following the recommendations of the Browne Review (2010), to an annual fee of up to $£ 9,000$ since September 2012. This has made the decision to undertake a degree, for many students, akin to a more conventional investment decision - in that it has an expected return. McGettigan (2013) states that: '[HE] effectively becomes a financial asset, an 'investment' that boosts future earnings...universities are then judged by how well they provide training that increases graduate earning profiles'. This means that choosing to attend HE has more of derived demand and introduces a strange risk/reward trade off. As HE is a one off purchase that cannot be tried before buying and whose benefits, or lack thereof, may only become apparent after many years, if the information being received by potential graduates is flawed, then the actual student experience and/or lack of employment will also lead to disappointment. Further, as both costs increase and become uncertain and returns fall and also become uncertain, attitudes towards the financial benefits of attending university will undoubtedly be affected. This will be especially the case for the lower socio-economic groupings who have a traditional dislike for taking on debt for education purposes (see Callender and Jackson 2005).

The introduction of fees has also had the additional effect of changing expectations and creating a ‘consumer culture’ in HE (see Jones 2010 Bates and Kaye 2014). Kandiko and Mawer (2013) provide evidence that students across all years and locations increasingly demand 'value for money' and that 'this was seen tangibly through sufficient contact hours and resources available and, abstractly through institutions' investment in students, learning spaces and the educational community' (page 5). In addition, Kandiko and Mawer found students desire 'a personalized higher education experience, with small teaching sessions, [with] opportunities to meet other staff and students' (page 9). Disappointment will emanate from pressures associated with expansion and the transformation of $\mathrm{HE}$ institutions from boutique providers to homogeneous programmes with large class sizes and cohorts.

We do have a guide to levels of disappointment with the actual university experience. As all UK academics know, this is attempted to be assessed by the relatively recently (2005) introduced National Student Survey. There are flaws with the survey but by 2011-2012 85 per cent of final year students stated that they were satisfied with their course (see HEFCE news archive 2012). In contrast, the Office of the Independent Adjudicator (OIA), which was established by the Higher Education Act 2004 (see http://www.oiahe.org.uk/about-us.aspx), 
reports that student complaints in England and Wales rose year on year from 2005 to 2012. The OIA received 542 complaints in 2005 and 2,012 in 2012; 2013 witnessed a slight drop, with 1,972 complaints received (see OIA Annual Report 2013, page 11).

Overall, we seem to have a conflation of issues. Parents and children in the UK are bombarded, via media and high school, with the notion that a degree confers a myriad of benefits, and this has become a deeply embedded conventional wisdom, which has led to massification. However, such expansion may have led to the erosion of the benefits and now the benefits themselves are being questioned. While selection of appropriate data remains both questionable and problematic what the past literature cannot fully establish is whether the benefits associated with HE ever existed and have dissipated (due to various changes regarding massification) and/or that the benefits ever existed for all graduates, across a wide range of socio-economic groups, due to methodological and interpretive errors. Significantly, individuals may base their decisions on the conventional wisdoms associated with undertaking a degree and that this, in turn, will affect societal expectations and perceptions. In addition, individuals may well be using past evidence on the premium that is out of date/unrepresentative by the time they decide, start and complete their studies. As Webb et al (2015) observe, perceptions of HE are a complex interaction of expectations and experiences, which have been brought into focus by uncertainty regarding fees and employment outcomes. If many graduates are increasingly having to take work in retail, coffee shops or bar work as the recent Baker Report suggests then this will obviously affect attitudes towards HE (see also see Walker and Zhu 2008).

\section{Data and Methodology}

In order to investigate attitudes towards $\mathrm{HE}$ we select and analyse answers to questions regarding attending a UK HE institution. Using the British Social Attitudes data for 2010, Table 1 shows our selected education variables which include answers to questions regarding: widening access to HE; whether $\mathrm{HE}$ is worth the time and money involved; whether $\mathrm{HE}$ is important to a young adult; whether a degree will garner financial benefits; whether it is perceived that a degree has non-pecuniary benefits; whether HE guarantees you a good job (or not) and whether perceptions regarding job prospects are changing and two questions examining the role of grants and fees. We initially disaggregate the data by socio-economic class to enable us to establish any social based HE perception differences. This is informed by the work of Kemp-King (2016) and Brown (2013) who believe that the reported average levels of returns to HE may be biased upon an individual's socio-economic background and the work 
of Ramsey (2008) who believes that the use of average graduate premium figures may misrepresent returns to sub-sections of society.

While not placing too much emphasis on Table 1 it does allow us to establish some general perception differences between those categorized as working class and the average for the sample. For example, the working classes are generally more in favour of widening access and are more likely to report that HE is not worth the time or money or that graduates will not end up better off financially. However, they have a higher positive response than all respondees to the question regarding whether a degree leads to a better job. The working classes also respond more positively to the use of student grants to subsidize $\mathrm{HE}$ and against the introduction of tuition fees. Interestingly, the working class respondees do not report higher than the average on issues of the non-pecuniary benefits of HE or on job prospects of graduates now compared to 10 years ago.

We investigate HE perceptions further by utilising a probit regression, using a stochastic frontier method to determine one of our explanatory variables - levels of wage underpayment. Our dependent variable is perceptions of financial returns to a bachelor degree - which is the answer to the question, shown in Table 1, that a university attender will not end up better off financially - in essence our dependent variable is the perception of the notion of the 'graduate premium' (see Conlon and Patrignani 2011Walker and Zhu 2013 or Naylor, Smith and Telhaj 2015). We then establish three independent variables to test the drivers of attitudes with respect to the financial value of UK HE. If respondees are reporting that a bachelor degree is not financially worthwhile, then we investigate whether this is due to: reduced job prospects; the changing cost environment, the reduction of grants and the introduction of tuition fees, or is it because graduates are not being paid in line with their human capital characteristics.

So, running the probit regression on the responses reported in Table 1 to the question 'the university attender will not end up better off financially', we establish the following empirical probit regression specification:

$$
V_{i}^{*}=\alpha+\beta_{S} S_{i}+\beta_{C} C_{i}+\beta_{D} D_{i}+\varepsilon_{i}
$$

Variable definitions and hypotheses development:

- $\quad V$ is an observed binary variable for $\mathrm{V}^{*}$ which equals one if the respondent i reports that a degree is not financially worthwhile; 
- $\quad S$ is a proxy variable which will help us establish Brown's (2013) theory of social congestion. It is a binary variable created by responses to the question 'students leaving university have worse job prospects nowadays than they had 10 years ago' (it equals one if the respondent deems that there are reduced employment opportunities for graduates). It provides a measure of perceptions of shifting underemployment in the graduate job market that could allude to congestion and individual perception that investment in university education will not necessarily generate degree-level employment. We hypothesize that this to be positive coefficient as unemployment becomes an increased possibility:

Hypothesis 1: $\beta_{\mathrm{s}}>0$; reduced graduate employment prospects will positively affect the belief that attending university is not financially beneficial;

- $\quad C$ allows us to control for the impact of changes in the cost environment. Again, it is a binary variable created by responses to the question 'all students should get grants to help cover their living costs' (equalling one if the respondent deems that grants should be offered in UK HE). It provides a measure of whether the re-introduction of grants would be a key element in the perception of the financial worth of attending university (increasing university take-up) and also helps us investigate the possible effects of reducing financial exposure. We hypothesize this to be a positive coefficient as graduates reporting concerns over the level of costs will affect attitudes towards the financial worth of attending university:

Hypothesis 2: $\beta_{\mathrm{c}}>0$; rising costs associated with a university education will positively affect the belief that attending university is not financially beneficial;

- $\quad D$ is a disappointment variable, allowing us to investigate the graduate premium or (more traditionally described as) the amount of wage level disappointment. In essence it captures the level of wage underpayment experienced and will help us shed further light on the 'average' graduate premium figure and, to some extent, where graduates gain employment. As discussed, if graduates are forced into non-graduate jobs such as retail, barista or bar work as The Baker Report or Walker and Zhu (2008) suggests, then they will not be receiving the commensurate payment associated with their human capital levels - there will be a level of underpayment. 
Generated through the application of the human capital model, the logic is that individuals will desire to be paid in line with their investment in their own human capital. This variable calculates levels of underpayment and captures disappointment with returns to education. It helps us to establish whether individuals are getting paid what they are fully worth given their human capital characteristics, including investment in HE. It is a continuous variable from zero to one. To interpret the results of this variable a reported underpayment of zero represents a respondent who is paid according to the maximum appropriate amount associated with their human capital levels. However, as the underpayment increases in magnitude, or as we report in Figure 1 as we move from left to right, the respondee is increasingly paid less than what they 'deserve' given their human capital characteristics.

As the estimation of underpayment is more methodologically complex we will discuss this further. Our underpayment measure is created using the methodology adopted in Watson (2000) which involves estimating the following stochastic frontier wage equation:

$$
\operatorname{In}\left(w_{i}\right)=\sum_{j=0}^{m} a_{j} x_{i j}+\sum_{k=0}^{n} b_{k} e_{i k}+\varepsilon_{i}+\phi_{i}
$$

where $w_{i}$ is respondent i's wage; $x_{i j}$ are control variables; $e_{i k}$ are education variables; $\varepsilon_{i}$ is a two-sided error and $N\left(0, \sigma_{\varepsilon}^{2}\right)$; and $\phi_{i}$ is a one-sided error $(\geq 0)$, used to capture underpayment, and has variance $\sigma_{\phi}^{2}$. We keep our analysis as simple as possible and use gender and age as controls given their known impact on wage rates. What we establish is a stochastic frontier with an exponentially distributed 1-sided error, on a wage equation (using log wage) controlling for education. The frontier measures levels of 'education disappointment' which is wages that are below the efficient frontier. Our results are presented in Table 2 which clearly show that HE, FE and a private education will positively impact wages and that having no qualifications will adversely affect wage outcomes. However, despite wage levels being positively influenced by HE, Figure 1 shows that levels of wage underpayment are quite high and indicates a widely distributed bell curve as we move from left to right. This is an interesting result and one which we hypothesize will affect perceptions of the worth of investment in HE. It is added to the probit model in order to capture levels of wage 'disappointment' - that is, reduced expectations based upon less than optimal wage levels based on human capital characteristics. We would expect a positive coefficient here as the rates of return to education 
are skewed - there are inequalities in educational return and the average is not indicative of individual outcome (see Ramsey 2008). Hypothesis 3 is therefore:

Hypothesis $3: \beta_{D}>0$; remuneration from attending university is skewed and wage underpayment will positively affect the belief that attending university is not financially beneficial.

\section{Results}

Table 3 shows the results of the probit analysis for our three explanatory variables and hypotheses. Results are presented with and without a non-pecuniary control variable. This variable, constructed from the survey question "there are more advantages to a university education than simply being paid more”, allows us to investigate whether respondents may report a lack of financial reward simply because of a focus on non-pecuniary outcomes. The non-pecuniary control estimate is found to have a negative sign. This therefore suggests that those who report non-pecuniary advantages to education are also those reporting pecuniary gains. Given this indicates that perceived pecuniary and non-pecuniary education gains are complementary, it is perhaps unsurprising that the non-pecuniary measure has no substantive impact on our results. All three explanatory variables for our hypothesis tests are positive and significant at the 1 per cent level. We therefore fail to reject any of our hypotheses.

Given we cannot reject hypothesis one, our results suggest that worsening graduate job opportunities may significantly restrict the perceived value of acquiring a degree. This finding provides evidence for Brown's (2013) theory of social congestion, underlining the notion that individuals feel the positioning power of a university education in the job market has declined as the UK has moved into an era of massification. In short, there are just too many degrees chasing too few degree-level jobs.

This result is also in line with two key conclusions from Webb et al (2015). The first is that respondents are more likely to report reduced HE-level opportunities over time. The second, in keeping with The Baker Report and Walker and Zhu (2008), is that there is tentative evidence of a belief that graduates may well end up in jobs that suggest a degree confers no additional financial value. More tangentially, the result may reflect dissatisfaction with both the lack of a personalised degree experience and the non-strengthening of key employment skills in the course of HE. Failure to prepare and position students for the job market is likely to further adversely affect perceptions in this way as HE is increasingly viewed within a consumerist culture (see McGettigan 2013). 
A decline in positioning power and the prevalence of a consumerist culture may also help explain our failure to reject hypothesis two. If a degree is viewed as a financial asset, complete with corresponding risks and rewards, then attitudes are again likely to be increasingly affected as uncertainty over future costs and income intensifies (see McGettigan (2013), Jones (2010) and Bates and Kaye (2014)). This issue is especially significant when one considers, for example, previous research that has shown the working class has an aversion to taking on debt (see Table 1 for evidence of this interpretation; see also Callender and Jackson (2005)). In the absence of a commensurate rising premium, rising costs are liable to augment perceptions of university attendance as financially risky.

This has potentially serious implications, foremost among them a marked polarization. In time it could be that only those willing and able to privately fund their studies or to take on the necessary debt will move into HE in the UK, leaving those unable to bear what they perceive to be the financial risks to enter the job market without a degree. Concomitantly, those who do attend university are likely to demand ever more value for money, further establishing a consumerist culture. This might lead to greater expectations of both the internal university experience and future earnings, with our findings becoming more entrenched if either of these prerequisites should not be met.

Moreover, as Brown (2013) has argued, middle-class families may become increasingly 'institutionally disappointed' as the supposed benefits of attending university go unrealized. In light of this, higher socio-economic classes could continue to invest in extra-curricular activities in order to secure places at higher-ranked UK universities; in tandem, universities themselves may be incentivized to divert spending away from scholarly activities and towards facilities and resources thought to better reflect students' ideas of an attractive learning environment (see Kandiko and Mawer (2013).

Our and third final hypothesis, regarding the nature of wage underpayment to graduates, also has worrying implications. To re-cap briefly: we estimated underpayment using a stochastic frontier technique and then included the results as an explanatory variable in our probit. Here the variable was again positive and significant, and we therefore fail to reject hypothesis three. Wage underpayment may significantly impact on attitudes over the value of acquiring a degree. Given the results also show underpayment can be substantial, our probit finding lends further support to the notion, as proposed by Ramsey (2008) and Adnett and Slack (2007), that past 
graduate premium studies based upon the average may be misrepresentative for certain socioeconomic groups.

Taken together, our results indicate an asymmetry between past research findings and our own, with the latter suggesting a different approach to analysing the graduate premium may be required. It could be that the premium exists but people do not believe it does because they or their friends have not earned a graduate job and so do not report that attending university is generally financially beneficial. This may be explained by an element of bounded rationality, reflecting how information is backward-looking and perceptions forward-looking. Individuals have only limited information when considering the financial returns to HE, and this might guide their responses: unaware of the graduate premium, they may simply assume the graduate job market is in decline and that this will inevitably affect financial outcomes. This being so, it might be argued that neither the past literature nor our own results can fully establish whether the financial benefits of attending university once existed but may have dissipated (due to various changes brought about by massification) or whether people believe the graduate premium does not exist because of the tightening of the graduate job market over the past decade.

However, what we may also be finding is that the premium is being captured by certain sections of society that are able to utilize their degree as part of a wider package of signals to employers to gain both a job and high remuneration. This interpretation provides support for Bourdieu's idea $(1971,1977)$ that certain socio-economic classes leverage their social and cultural capital to obtain better outcomes from attending university. It also provides us with an explanation for the recent positive and negative research on the graduate premium: both may well be correct, in so far as it is possible that an average graduate premium does exist but, because it is being captured chiefly by those from higher socio-economic backgrounds (see Kemp-King (2016) and Naylor et al (2015)), cannot be considered truly representative.

\section{Conclusions and implications}

We set out to investigate attitudes regarding the financial returns to attending a UK HE institution - helping to inform the debate traditionally based around a substantial graduate premium. We find that many in society now believe that attending HE may not confer financial rewards and that this may be due to a lack of graduate job prospects, the rise in tuition fees and 
wage underpayment. The current environment seems to be fuelling uncertainty which, as with any investment, may well reduce demand for HE in the future.

In addition, within this increasingly uncertain environment, the rise in tuition fees and the reduction in grants will most likely affect those who do not have access to capital to fund their education and may therefore be unwilling to borrow. Thus, the working class who neither have access to a funding source, and have aversion to taking on debt, may decide not to attend university as they believe it confers no financial benefit. Those middle class who have access to funds, and view HE as more than just financially rewarding may continue to attend and, as evidence shows, may begin to evolve their behaviour to ensure job prospects and financial returns. This may involve the middle classes increasingly engaging in the use of private education and private tutors to ensure entry into Oxbridge or the Russell Group Universities and the use of extra-curricular activities to distinguish themselves from the other socioeconomic groups and signal their worth to future employers. As such, in line with the observations of Bourdieu (1971 and 1977) it could be expected that they may place greater emphasis upon social and cultural capital to secure the benefits from HE not available to others in society. Those engaging in HE see a degree as just one piece of the jigsaw in 'positioning' themselves to gain an advantageous outcome regarding employment, remuneration and better life outcomes in general.

As Webb et al (2015) observe, the middle class have shown themselves to be adept at maintaining their position in society: 'More than five decades of pro-HE policies have seen the relative participation of disaggregated socio-economic groups remain remarkably stable. HE is still dominated by the higher social-economic groups, and intergenerational social mobility remains limited'. Interestingly, we may have entered an era where the middle class are increasingly competing against themselves for better life outcomes as Brown (2013) states 'the sources of conflict as experienced by middle-class youth may not be expressed in class or gender terms...but as a conflict around the institutions of education, employment and the job market'. Falling employment opportunities have meant that many middle class families believe it essential to gain entry to the best universities and are thus competing with themselves to get there. We may well see, or indeed are seeing, an increase in intra class conflict.

The university sector may also become increasingly polarized as a select group of universities to which society confers worth (again, Oxbridge and the Russell Group) may receive the highest demand from school leavers and may therefore have access to greater resource to invest 
in future developments - both academic and infrastructure. Conversely, as many, less privileged individuals, choose not to attend university those universities outside this group may become increasingly financial squeezed. This is evidenced from the American experience where those that graduate from a growing number of sub-standard educational institutions do so with severely limited job prospects and crushing levels of debt (see Mettler 2014).

Another consequence is that universities may have to become increasingly demand driven focusing upon the quality of their teaching provision, their links with employers and their overall worth to the student. As a degree becomes increasingly seen through a consumerist lens, value for money will become paramount - even to those investing in extra-curricular activities. The recently introduced Teaching Excellence Framework with clearly have a central part to play and we could expect a continued spend on infrastructure to signal quality.

Each of these implications alone demands reflection. Taken together, they speak of a HE sector in which the declining value attached to a degree threatens far-reaching consequences in both the sphere of HE itself and the world of employment that lies beyond. The evidence increasingly suggests that significant shifts are already under way.

\section{References}

Adnett, N. and Slack, K. 2007. “Are There Economic Incentives for Non-Traditional Students to Enter HE? The Labour Market as a Barrier to Widening Participation” Higher Education Quarterly 61 (1) January: 23-36.

Altbach, P. G. 1999. “The Logic of Mass Higher Education”, Tertiary Education and Management. 5 (2): 105-24.

Bates, E. A., and Kaye, L. K. 2014. “'I'd be Expecting Caviar in Lectures': The Impact of the New Fee Regime on Undergraduate Students Expectations of Higher Education.” Higher Education 67 (5): 655-73.

Battu, H., C. R. Belfield, and P. J. Sloane. 2003. "Human Capital Spillovers within the Workplace: Evidence for Great Britain.” Oxford Bulletin of Economics and Statistics 65 (5): 575-94.

Blundell, R., L. Dearden, and B. Sianesi. 2005. "Measuring the Returns to Education.” In What's the Good of Education? edited by S. Machin and A. Vignoles, pp. 117-45. Princeton: Princeton University Press.

Bolton, P. 2012. Education: Historical Statistics. Standard Note. Library of the House of Commons. SN/SG/4252.

Brown, P. 2013. "Education, Opportunity and the Prospects for Social Mobility.” British Journal of Sociology of Education 34 (5-6): 678-700. 
Browne Report. 2010. Securing a Sustainable Future for Higher Education - an Independent Review of Higher Education Funding and Student Finance. London.

Callender, C and J. Jonathan (2005) Does the fear of debt deter students from higher education? Journal of Social Policy, 34 (4): 509-540.

Chesters, J. and Watson, L. 2014 "Returns to education for those returning to education: evidence from Australia” Studies in Higher Education. 39, (9): 1634-1648.

Conlon, G., and Patrignani, P., 2011. “The Returns to Higher Education Qualifications”, BIS Research Paper Number 45.

Dearing Report. 1997. National Committee of Inquiry into Higher Education. Department for Business, Information and Skills. 2012. Statistical First Release, Academic Year 2010/11 (Provisional). London: BIS.

Department for Education and Skills. 2006. Widening Participation in Higher Education. Nottingham: Department for Education and Skills.

Dickson, M., Harmon, C. 2011. "Economic returns to education: What We Know, What We Don't Know, and Where We Are Going - Some brief pointers", Economics of Education Review. Vol. 30. Pages 1118-1122.

Gorard, S. 2008. "A re-consideration of rates of 'social mobility' in Britain: or why research impact is not always a good thing”, British Journal of Sociology of Education. 29 (3): 317-324,

Gorard, S., E. Smith, H. May, L. Thomas, N. Adnett, and K. Slack. 2006. Review of Widening Participation Research: Addressing the Barriers to Participation in Higher Education. A report to HEFCE. The University of York, Higher Education Academy and Institute for Access Studies.

Greenaway, D. and Haynes, M. (2003). "Funding Higher Education in the UK: The Role of Fees and Loans”, The Economic Journal, 113 (485), pp.F150 -F166.

HEFCE (Higher Education Funding Council for England). 2012. Highest Ever Satisfaction Rates in 2012 Student Survey.

http://www.hefce.ac.uk/news/newsarchive/2012/news75522.html.

Jobbins, D. 2014. "Starting salaries for graduate jobs decline as economic downturn bites”, The Complete University Guide: http://www.thecompleteuniversityguide.co.uk/news/startingsalaries-for-graduate-jobs-decline-as-economic-downturn-bites/

Jones, G. 2010. "Managing Student Expectations: The Impact of Top-up Tuition Fees.” Perspectives 14 (2): 44-48.

Kandiko, C. B., and M. Mawer. 2013. Student Expectations and Perceptions of Higher Education: Executive Summary. London: King's Learning Institute.

Kemp-King, S. 2016. “The Graduate Premium: Manna, Myth or Plain Mis-selling?” Intergenerational Foundation. August. 
Lochner, L. and Moretti, E. 2004. "The Effect of Education on Criminal Activity: Evidence from Prison Inmates, Arrests, and Self-Reports” American Economic Review, 94(1): 155-89

Lord Baker of Dorking (Chair) 2014. “The Skills Mismatch”, The Edge Foundation: http://www.edge.co.uk/media/130721/the_skills_mismatch_march_2014_final.pdf

McGettigan, A. 2013. The Great University Gamble. Pluto Press.

Metcalfe, R., and P. J. Sloane. 2007. Human Capital Spillovers and Economic Performance in the Workplace in 2004: Some British Evidence. Bonn: Institute for the Study of Labor (IZA).

Mettler, S. 2014. Degrees of Inequality: How the Politics of Higher Education Sabotaged the American Dream. Basic Books.

Million+. 2013. What's the Value of a UK Degree? London: Million+ and London Economics.

Mountford-Zimdars, A., S. Jones, A. Sullivan, and A. Heath. 2013. "Framing Higher Education: Questions and Responses in the British Social Attitudes Survey, 1983-2010." British Journal of Sociology of Education 34 (5-6): 792-811.

Naylor, R., Smith, J., Telhaj, S., 2015. "Graduate Returns, Degree Class Premia and Higher Education Expansion in the UK”, CEP Discussion Paper No 1392. November.

Office of the Independent Adjudicator. 2013. Annual Report. Reading.

Ramsey, A. 2008. "Graduate Earnings: An econometric analysis of returns, inequality and deprivation across the UK”, Department for Employment and Learning, Northern Ireland.

Roulin, N. and Bangerter, A. 2013. "Students' use of extra-curricular activities for positional advantage in competitive job markets”, Journal of Education and Work. 26(1): 21-47.

Thompson, R., and R. Simmons. 2013. "Social Mobility and Post-compulsory Education: Revisiting Boudon's Model of Social Opportunity.” British Journal of Sociology of Education 34 (5-6): 744-65.

Vignoles , A. and Murray, N. 2016. Widening Participation in Higher Education. Education Sciences. Vol. 6. No. 13.

Walker, I. and Zhu, Y. 2008. "The College Wage Premium and the Expansion of Higher Education in the UK”, The Scandinavian Journal of Economics, 110(4): 695-709.

Walker, I. and Zhu, Y. 2013. "The Impact Of University Degrees On The Lifecycle Of Earnings: Some Further Analysis” BIS Research Paper Number 112.

Waston, D. 2000. “In Search of the Poor”, Journal of Economic Psychology. 21(5) October: 495-515.

Webb, R., Watson, D., Cook, S., and Arico, F. 2015. "Graduate views on access to higher education: is it really a case of pulling up the ladder?” Studies in Higher Education. Vol. 42. Issue 3. Pages 505-518. 
Wolf, A. (2002) 'We're still skipping (working) class'. The Times Higher Educational Supplement, Vol. 24, May, 18-19. 